\title{
Ipomoea pes-caprae Mediated Silver Nanoparticles and their Antibacterial Effect
}

\author{
K. Satyavani, S. Gurudeeban, T. Ramanathan and T. Balasubramanian \\ Centre of Advanced Study in Marine Biology, Faculty of Marine Sciences, Annamalai University, Parangipettai 608502, \\ Tamil Nadu, India
}

\begin{abstract}
Nanoparticle synthesis by using plant sources is a great deal of attention due to their potential in biological and pharmaceutical applications. In the present investigation, we synthesis silver nanoparticles using leaf extract of Ipomoea pes-caprae (L.) R.Br. and their antimicrobial activity against urinary tract infectious pathogens were studied. The reduction of aqueous silver nitrate ions during reaction with Ipomoea pes-caprae extract was tracked by monitoring changes in color from greenish to reddish brown. Synthesized nanoparticles were characterized by UV-Spectrophotometer, Scanning Electron Microscope and Fourier Transform Infrared spectroscopy. The pathogens collected from Urinary tract infectious patients for antimicrobial studies. UV-visible absorption spectra give a sharp peak specific at $330 \mathrm{~nm}$. The synthesized silver nanoparticles were generally found to be rectangular and irregular in shape with variable size ranging from $2-45 \mathrm{~nm}$ as evident by SEM. FT-IR peaks were in the extract ranging from $500-4000 \mathrm{~cm}^{-1}$ which confirmed the presence of polyphenolic components on to silver nanoparticles. The silver nanoparticles showed potential antibacterial effect against urinary tract infectious microbes E. coli, P. aeruginosa, $K$. pneumonia, Enterobacter sp. and $S$. aureus. The results suggest that the application of biological synthesis silver nanoparticles against infectious bacteria provide a platform for production of broad spectrum antibiotics with cost effective and non-toxic manner.
\end{abstract}

Key words: Coastal sand dune, FT-IR, nanoparticles, $P$. aeruginosa

Science International 1 (5): 155-159, 2013

\section{INTRODUCTION}

Ipomoea pes-caprae belongs to the Convolvulaceae family which grows wild on ocean shores of India and world wide distributed. It is as a sand binder growing down at high drought and saline stresses. This full sun plant will prosper on most well-drained soils. The Beach Morning Glory will tolerate very high levels of salt spray but cannot endure over watering. Basically, plant it, water a few times and leave the sprinkler off ${ }^{1}$. Worldwide, Ipomoea pes-caprae is used as an infusion for urinary or kidney complaints, hypertension, skin infections caused by Mycobacterium tuberculosis and in decoctions to treat functional digestive disorders, internal pain, colic, lumbago, dysentery, arthritis, rheumatism and other inflammatory conditions ${ }^{2,3}$. In Mexico, the herbal drug Ipomoea pes-caprae is called "rinonina" and comes from the Spanish word "rinon", which means kidney and reflects the belief of traditional healers that it moderates the "heat" of an infected kidney". Nanoparticles usually

Corresponding Author: T. Ramanathan, Centre of Advanced Study in Marine Biology, Faculty of Marine Sciences, Annamalai University, Parangipettai, Tamil Nadu, India Tel: 04144-243223 Ext 213 Fax: 04144-243555 referred as particles with a size up to $100 \mathrm{~nm}^{5}$. Nanoparticles exhibit completely new or improved properties based on specific characteristics such as size, distribution and morphology. Specific surface is relevant for catalytic reactivity and other related properties such as antimicrobial activity in silver nanoparticles. As specific surface area of nanoparticles is increased, their biological effectiveness can increase in surface energy. Silver has long been recognized as having an inhibitory effect towards many bacterial strains and micro organisms commonly present in medical and industrial processes? $^{\text {? }}$ The most widely used and known applications of silver and silver nanoparticles are in medical industry. These include topical ointments and creams containing silver to prevent infection of burns and open wounds. Production of nanoparticles can be achieved through different methods. Chemical approaches are the most popular methods for the production of nanoparticles. However, some chemical methods cannot avoid the use of toxic chemicals in the synthesis protocol. Since noble metal nanoparticles such as gold, silver and platinum nanoparticles are widely applied to human contacting areas, there is a growing 
need to develop environmentally friendly processes of nanoparticles synthesis that do not use toxic chemicals. Biological methods of nanoparticles synthesis using micro-organisms ${ }^{9}$, enzyme ${ }^{10}$, plant or plant extract have been suggested as possible ecofriendly alternatives to chemical and physical methods. Using plant for nanoparticles can be advantageous over other biological process $^{11}$. It can also suitably scaled up for large-scale synthesis of nanoparticles. The synthesis of pure metallic nanoparticles of silver by the reduction of $\mathrm{Ag}^{+}$and $\mathrm{Au}^{3+}$ ions using Neem (Azadirachta indica) leaf broth ${ }^{12}$. If biological synthesis of nanoparticles can compete with chemical methods, there is a need to achieve faster synthesis rates. In our laboratory we synthesized silver nanoparticles from leaf and callus extract of Citrullus colocynthis also reported its moderate antimicrobial activity against biofilm forming bacteria ${ }^{13}$, anti-cancer effect on Hep-2 cell line ${ }^{14}$ and leaf extract of salt marsh plant Suaeda monoica exhibited anti-cancer effect on Hep-2 cell line ${ }^{15}$. The exact mechanism of silver nanoparticles synthesis by plant extracts is not yet fully understood. Only participation of phenolics, proteins and reducing agents in their synthesis has been speculated. In the present study, we screened coastal sand dune species Ipomoea pes-caprae leaf extracts for extracellular nanoparticles synthesis, characterized by using UV-visible spectroscopy, SEM, FT-IR and analysis the antimicrobial therapeutics of silver nanoparticles against urinary track infectious bacteria.

\section{MATERIALS AND METHODS}

Plant material and preparation of the extract: Fresh Ipomoea pes-caprae leaves were collected from the sandy shore of Parangipettai coastal region (Southeast coast of India). The specimen was botanically certified and a voucher specimen (AUCASMB 68) deposited in the Herbarium of Centre of Advanced Study in Marine Biology, Faculty of Marine Sciences, Annamalai University, India. The experimental chemicals were purchased from Sigma Chemicals (Mumbai).

Eco friendly synthesis of silver nanoparticles: Plant mediated silver nanoparticles synthesis was followed by the method of Satyavani et al $l^{15}$. After $5 \mathrm{~h}$ of incubation the silver nanoparticles were isolated and concentrated by repeated (4-5 times) centrifugation of the reaction mixture at $10,000 \times \mathrm{g}$ for $10 \mathrm{~min}$. The supernatant was replaced by distilled each time and suspension stored as lyophilized powder.

Characterization by UV-Vis spectrophotometer: The optical measurements, was carried out by UV-Vis spectrophotometer (UV-2450 (Shimadzu) and scanned the spectra between $200-700 \mathrm{~nm}$ at the resolution of $1 \mathrm{~nm}$.
Scanning electron microscopy: Hitachi S-4500 SEM machine was used to characterize the morphology of Silver nanoparticles. Thin films of the sample were prepared on a carbon coated copper grid by just dropping a very small amount of the sample on the grid, extra solution was removed using a blotting paper and then the film on the SEM grid were allowed to dry by putting it under a mercury lamp for $5 \mathrm{~min}$. The images were captured in SEM mode at the desired magnification.

Fourier transform infra-red spectroscopy: To identify silver nanoparticles associated biomolecules, the Fourier transform infra red spectra of washed and purified Silver nanoparticles powder were recorded on the Nicolet Avatar 660 FT-IR Spectroscopy (Nicolet, USA) using $\mathrm{KBr}$ pellets. To obtain good signal to noise ratio, 256 scans of Silver nanoparticles were taken in the range of $400-4000 \mathrm{~cm}^{-1}$ and the resolution was kept as $4 \mathrm{~cm}^{-1}$.

Isolation of urinary tract infectious (UTI) bacterial pathogens: A total of 25 urine samples from female patients admitted in the hospital as urinary tract infectious problem from (RMMCH) Rajah Muthiah Medical College and Hospital, Annamalai Nagar, Tamil Nadu, in a separate sterile wide mouth bottle. Before collecting the samples the women were instructed to swab the vulvae. Mid strain urine was collected in a sterile wide mouth container. For the isolation of UTI strains, loopful of urine samples were streaked in to the nutrient agar, Mac conkey agar, blood agar and Chocolate agar plates and incubated at $37 \pm 2^{\circ} \mathrm{C}$ for $24 \mathrm{~h}$. Next day individual colonies were selected and identified on the basis of morphological characteristics, gram staining and biochemical characters ${ }^{16,17}$.

\section{RESULTS AND DISCUSSION}

Synthesis of Silver nanoparticles: The reaction started with in first hour of the incubation with aqueous $1 \mathrm{mM}$ silver nitrate solution. This was confirmed by the appearance of brown color in the reaction mixture. The reaction rate was maximum after $25 \mathrm{~h}$ of incubation as indicated by the formation of silver nanoparticles. Our findings showed resemblance to the results already reported by in the case of extract of Aloe vera ${ }^{18}$. They reported that when the extracts of their respective test plants were challenged with silver nitrate $(1 \mathrm{mM})$. They turned brown and the intensity of color was increased with the time of incubation.

Characterization of synthesized silver nanoparticles: The reduction of aqueous silver nitrate ions during reaction with Ipomoea pes-caprae extract was tracked by monitoring changes in color with UV-Vis 


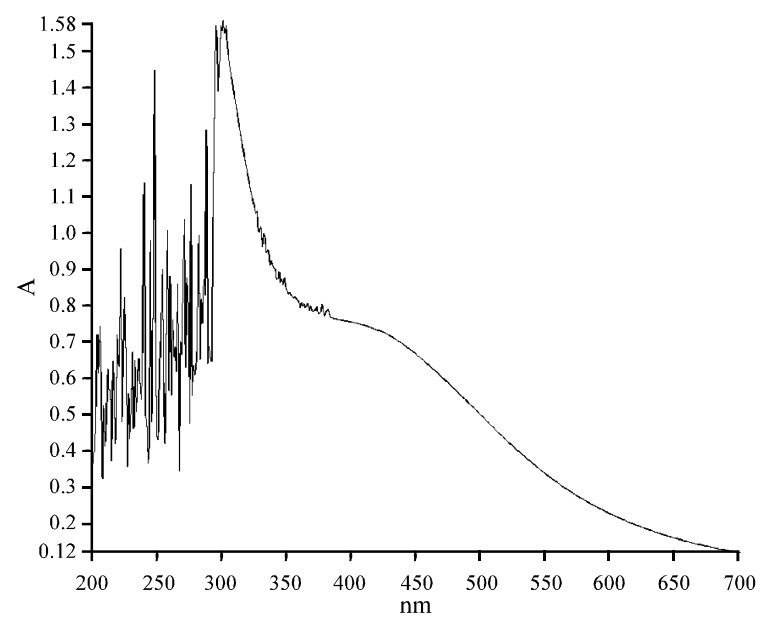

Fig. 1: UV-absorption spectra recorded from Ipomoea pes-caprae mediated silver nanoparticles SEM characterization

spectroscopy. Figure 1 shows, a sharp peak specific for the synthesis of silver nanoparticles was obtained at $330 \mathrm{~nm}$ and arises due to the excitation of surface plasmon vibrations in the synthesized silver nanoparticle. Silver nanoparticles in aqueous phase are extremely stable with no precipitation and the stability for such a long period is seems to be due to antimicrobial properties $^{19}$ of this plant. This outcome showed resemblance with a sharp peak found at $340 \mathrm{~nm}$ in the case of silver nanoparticles synthesized from one of the medicinally valuable coastal sand dune creeper of Citrullus colocynthis leaf extract.

Scanning electron microscopy morphological characterization of $\mathrm{SNP}^{20}$ the shape of the silver nanoparticles synthesized by leaf extract was mixture of sphere and plates, found to be in the range of $2-45 \mathrm{~nm}$ shown in the Fig. 2. Finally, confirmed the synthesis of rectangular and irregular shaped silver nanoparticles in the reaction mixture. The larger size of the nanoparticles might be due to the capping of nanoparticles by protein with aromatic ring and bound amide as confirmed from FT-IR analysis. Because of a relatively large surface area, the silver nanoparticles may easily interact with other particles and increase with other particles and increase their antimicrobial efficiency.

In our study, FT-IR spectra were obtained with Avatar-330 FT-IR spectroscopy using $\mathrm{KBr}$ pelleting. FT-IR measurements were carried out to identify the possible biomolecules responsible for the reduction of the $\mathrm{Ag}^{+}$ions and capping agent responsible for the stability of biogenic nanoparticle solution. Figure 3 represents the FTIR spectrum of synthesized SNp from Ipomoea pes-caprae which shows prominent absorption bands at 2929.87, 2343.51, 2046.47, 1637.56, 1415.75,

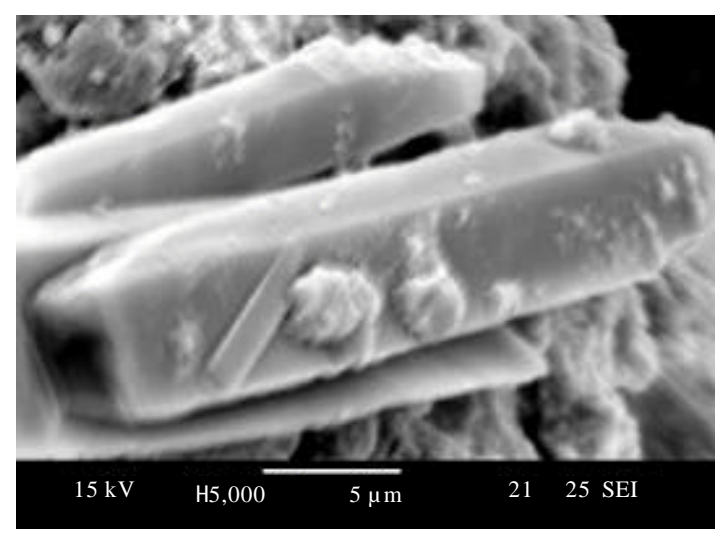

Fig. 2: Representative SEM images of Ipomoea pes-capraereduced silver nanoparticles at desired magnification rectangular shape FT-IR

$1039.63,655.80 \mathrm{~cm}^{-1}$. Among them, the absorption peak at $2929.87 \mathrm{~cm}^{-1}$ can be assigned as absorption peaks of $\mathrm{CH}$ stretch several bands (alkyl), the peak at $1637.56 \mathrm{~cm}^{-1}$ is associated with stretch vibration of $-\mathrm{C}=\mathrm{C}$ - and is assigned to the amide 1 bonds of proteins. The peak at 1039.63 can be assigned as $\mathrm{C}-\mathrm{O}$ stretch $(\mathrm{CH}-\mathrm{O}-\mathrm{H}$ in cyclic alcohols). The peak at $655.80 \mathrm{~cm}^{-1}$ which represents the aromatic ring $\mathrm{C}-\mathrm{H}$ vibrations, indicate the involvement of free catechin ${ }^{21}$. This suggests the attachment of some polyphenolic components on to silver nanoparticles. This means the polyphenols attached to silver nano particles may have at least one aromatic ring.

Antibiotic effect of silver nanoparticles: The use of metallic silver as an antimicrobial agent has been recognized for centuries. Thus, $0.5 \%$ silver nitrate solution has been recognized as a good topical antibacterial agent based on various in vitro and in vivo studies indicating its ability to inhibit bacterial growth without exhibiting any toxic effect on epidermal cells. Out of the 25 midstream urine samples, 15 bacterial isolates were recovered and the biochemical tests revealed that, these isolates belong to 5 species (Table 1). Of these $E$. coli is the predominant one (45\%); $P$. aeruginosa (23\%), K. pneumonia (20\%), Enterobacter sp. (8\%) and $S$. aureus (4\%). The antibacterial effect can be so great that one gram of silver nanoparticles is all that is required to give antibacterial properties to hundred of square meters of substrate material (Table 2). The antibacterial property of silver nanoparticles (size ranges from 25-50 nm) towards a broad spectrum of gram negative and gram positive bacteria including multi-drug resistant strains ${ }^{22}$. 


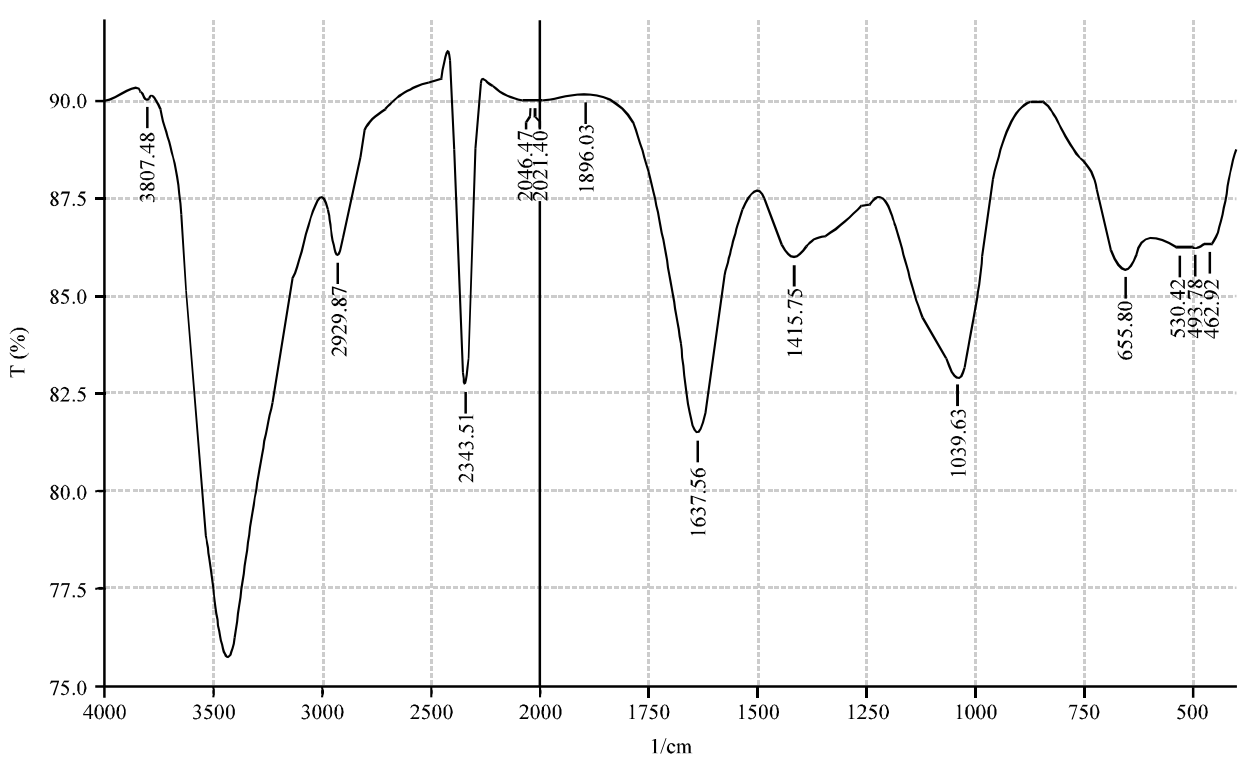

Fig. 3: FT-IR spectrum of silver nanoparticles synthesized from Ipomoea pes-caprae leaf extract with $1 \mathrm{mM}$ silver nitrate solution

Table 1: Biochemical characterization of isolated bacteria from UTI (urinary tract infectious patients)

\begin{tabular}{|c|c|c|c|c|c|}
\hline Characteristics & P. aeruginosa & E. colit & K. pneumoniae & Enterobactersp. & S. auteus \\
\hline Gram staining & - & - & - & - & + \\
\hline TSI & Slant- & Slant- & Slant+ & Slant+ & - \\
\hline & Butt+ & Butt- & Butt+ & Butt- & \\
\hline Mannitol & Acid & Acid & Acid & Acid & \\
\hline Motility & Motile & Motile & non-Motile & Motile & Motile \\
\hline Indole test & - & + & - & - & - \\
\hline Methyl red test & + & + & - & - & - \\
\hline V.P. test & - & - & + & + & - \\
\hline Citrate test & - & - & + & + & - \\
\hline Urease test & + & - & + & - & - \\
\hline Oxidase test & + & - & - & - & - \\
\hline Catalase test & + & - & - & - & - \\
\hline $\mathrm{H}_{2} \mathrm{~S}$ & - & - & - & - & - \\
\hline
\end{tabular}

$+:$ Positive, -: Negative

Table 2: Antibacterial activity of silver nanoparticles against urinary tract infectious pathogens

\begin{tabular}{lc}
\hline Bacterial strains & Zone of inhibition against silver nanoparticles \\
\hline E. colf & $8.25 \pm 0.65$ \\
P. aeruginosa & $6.15 \pm 0.25$ \\
K. pneumonia & $6.30 \pm 0.72$ \\
Enterobactersp. & $7.20 \pm 0.46$ \\
S. aureus & $6.50 \pm 0.280$ \\
\hline
\end{tabular}

Data represented as Mean \pm SD $(n=3)$

In addition to size and concentration of the nanoparticles, the shape of the silver nanoparticles has significant effect on the antibacterial efficacy ${ }^{23}$. The study demonstrated the ability of colloidal silver to inhibit the growth and multiplication of bacterial strains including multi-drug resistant strains. As compared to other biological systems the plant system shows rapid and easy biosynthesis of nanoparticles. The synthesis of silver nanoparticles by the extract of Ipomoea pes-caprae may therefore, serve as a green simple, cheap and eco-friendly approach.

\section{CONCLUSION}

In conclusion, the bio reduction of aqueous $\mathrm{Ag}^{+}$ions by the leaf extract of the Ipomoea pes-caprae has been demonstrated. This green chemistry approach toward the synthesis of silver nanoparticles has applied on antimicrobial agents to bactericidal, wound healing and urinary tract microbes.

\section{ACKNOWLEDGMENTS}

The authors are gratefully acknowledged to the authorities of Annamalai University and DST-PURSE program, Govt. of India, New Delhi for providing financial support during the study period. 


\section{REFERENCES}

1. Edward Gilman, F., 1999. Ipomoea pes-caprae. Co-Operative Extensive Service, Institute of Agricultural Science. Fact Sheet FPS-283. http:/hort.ufl.edu/database/documents/pdf/shrub_ fact_sheets/ipopesa.pdf

2. De Souza, M.M., A. Madeira, C. Berti, R. Krogh, R.A. Yunes and V. Cechinel-Filho, 2000. Antinociceptive properties of the methanolic extract obtained from Ipomoea pes-caprae (L.) R. Br. J. Ethnopharmacol., 69: 85-90.

3. Pongprayoon, U., P. Baeckstrom, U. Jacobsson, M. Linstrom and L. Bohlin, 1992. Antispasmodic activity of beta-damascenone and E-phytol isolated from Ipomoea pes-caprae. Planta Med., 58: 19-21.

4. Pereda-Miranda, R., E. Escalante-Sanchez and C. Escobedo-Martinez, 2005. Characterization of lipophilic pentasaccharides from beach morning glory (Ipomoea pes-caprae). J. Nat. Prod., 68: 226-230.

5. Nalwa, H.S., 2005. Handbook of Nanostructured Biomaterials and Their Applications in Nanobiotechnology. American Scientific Publishers, Los Angeles, pp: 1-2.

6. Jhan, W., 1999. Chemical aspects of the use of gold clusters in structural biology. J. Struct. Biol., 127: 106-112.

7. Murphy, C.J., 2008. Sustainability as an emerging design criterion in nanoparticle synthesis and applications. J. Mater. Chem., 18: 2173-2176.

8. Schultz, S., D.R. Smith, J.J. Mock and D.A. Schultz, 2000. Single-target molecule detection with nonbleaching multicolor optical immunolabels. Proc. Natl. Acad. Sci., 97: 996-1001.

9. Nair, B. and T. Pradeep, 2002. Coalescence of nanoclusters and formation of submicron crystallites assisted by Lactobacillus strains. Cryst. Growth Des., 2: 293-298.

10. Willner, I., R. Baron and B. Willner, 2006. Growing metal nanoparticles by enzymes. Adv. Mater., 18: $1109-1120$.

11. Taleb, C., M. Pettai and P. Pileni, 1998. Nano particles and nano structured films preparation. Characterization Appl. Chem., 22: 1203-1203.

12. Shankar, S.S., A. Rai, A. Ahmad and M. Sastry, 2004. Rapid synthesis of $\mathrm{Au}, \mathrm{Ag}$, and bimetallic Au core-Ag shell nanoparticles using Neem (Azadirachta indica) leaf broth. J. Colloid Interface Sci., 275: 496-502.
13. Satyavani, K., S. Gurudeeban, T. Ramanathan and T. Balasubramanian, 2011. Biomedical potential of silver nanoparticles synthesized from calli cells of Citrullus colocynthis (L.) schrad. J. Nano. Biotechnol., Vol. 9.

14. Satyavani, K, S. Gurudeeban, T. Ramanathan and T. Balasubramanian, 2012. Toxicity study of silver nanoparticles synthesized from Suaeda monoica on Hep-2 cell line. Avi. J. Med. Biotech., 4: 35-39.

15. Satyavani, K., T. Ramanathan and S. Gurudeeban, 2011. Green synthesis of silver nanoparticles by using stem derived callus extract of bitter apple (Citrullus Colocynthis). Dig. J. Nanomaterials Biostructures, 6: 1019-1024.

16. Thomas, J.G., 1995. Urinary Tract Infections. In: Text Book of Diagnostic Microbiology, Mahon, C.R. and Jr. G. Manuselis (Eds.). W.B. Saunders Co., Philadelphia, USA., pp: 949-969.

17. Cheesbrough, M., 2002. District Laboratory Practice in Tropical Countries. Part 2, Cambridge University Press, Cambridge, UK., ISBN: 0-521-66546-9, pp: 157-234.

18. Chandran, S.P., M. Chaudhary, R. Pasricha, A. Ahmad and M. Sastry, 2000. Synthesis of gold nanotriangles and ag nanoparticles using aloe vera plant extract department of biotechnology, bharathidasan university, tiruchirappalli-620024. TN India. Biotechnol. Prog., 22: 577-583.

19. Bragadeeswaran, S., K. Prabhu, S.S. Rani, S. Priyadharsini and N. Vembu, 2010. Biomedical application of beach morning glory Ipomoea pes-caprae. Int. J. Trop. Med., 5: 81-85.

20. Sing, M., I. Sinha and R.K. Mandal, 2009. Role of pH in the green synthesis of silver nanoparticles. Mat. Lett., 63: 425-427.

21. Krishnan, R. and G.B. Maru, 2006. Isolation and analyses of polymeric polyphenols fractions from black tea. Food Chem., 94: 331-340.

22. Panacek, A., L. Kvitek, R. Prucek, M. Kolar and R. Vecerova et al, 2006. Silver colloid nanoparticles: Synthesis, characterization and their antibacterial activity. J. Phys. Chem. B, 110: 16248-16253.

23. Lara, H.H., N.V. Ayala-Nunez, L.C.I. Turrent and C.R. Padilla, 2010. Bactericidal effect of silver nanoparticles against multidrug-resistant bacteria. World J. Microbiol. Biotechnol., 26: 615-621. 